\title{
Investigating the Mechanical Properties of Reinforced Coconut Shell Powder/Epoxy Resin Composites
}

\author{
AM Andezai ${ }^{1}$, LM Masu $^{1}$ and M Maringa ${ }^{2}$ \\ ${ }^{1}$ Vaal University of Technology, Faculty of Engineering and Technology, Department of Mechanical Engineering, \\ Private Bag X021, Vanderbijlpark, Andries Potgieter Blvd, 1911, South Africa. \\ ${ }^{2}$ Central University of Technology, Faculty of Engineering and Technology, Department of Mechanical and Mechatronics \\ Engineering, Private Bag X20539, Bloemfontein, 9300, South Africa.
}

ORCID: 0000-0003-0154-8572 (Andekuba Andezai)

\begin{abstract}
Experimental investigations were conducted to determine the mechanical properties of coconut shell powder filled epoxy resin composites. The results obtained showed that the modulus of elasticity and hardness of the composite increased with increasing percentage weight of both the $150 \mu \mathrm{m}$ and $212 \mu \mathrm{m}$ CSP particle sizes. The tensile strength, percent elongation and impact toughness of the composite were all seen to decrease as the reinforcement increased. The investigations carried out showed that the addition of coconut shell powder to epoxy resin only raised the values of the specific mechanical properties of tensile stiffness and hardness. Different models were used to predict the mechanical properties of the CSP composites. The method of Nicolais-Narkis predicted values of tensile strength that depicted a decreasing trend with increasing weight fraction of the reinforcing filler, in a manner similar to that of the experimental results obtained here. Nielsen's equation gave rise to predicted values of percentage elongation that were much less than the experimental results obtained in the present work. Einstein's and Voigt equations predicted values of tensile stiffness that were higher than the experimental values obtained here, whilst the Reuss equation predicted values that were lower than these experimental values. The model of Guth and separately Smallwood predicted values that were closest to the experimental values obtained here.
\end{abstract}

Keywords: Weight percentage, coconut shell powder, particle, matrix, reinforcement, tensile strength, hardness, and density

\section{INTRODUCTION}

There is a growing focus on the use of naturally occurring biodegradable plant fibres such as jute, cotton, bamboo, banana, sisal, and coconut shell as reinforcement for composites to produce eco-friendly industrial products [1]. Bio-composites offer environmental advantages such as reduced dependence on non-renewable energy, lower emission of pollutants, lower emissions of greenhouse gases, and enhanced recovery of energy [2]. Green composites which consist of natural fibres and biodegradable resins are being developed presently as substitutes to non-environmentally friendly materials such as conventional plastics (petroleum derived polymers) and have the required values of mechanical properties specific to various applications [3]. In the case of automobile components, fibres including bamboo, hemp and kenaf which are light, strong, renewable, and inexpensive have been used in certain requirements instead of glass fibres [4]. These fibres are less expensive compared to other materials such as steel, aluminium, wood, and granites [2, 3].

Natural fillers and fibres reinforced thermoplastic composites have successfully proven their high qualities in various fields of technical application. As replacements for conventional synthetic fibres such as aramid and glass fibres. Natural fibres are increasingly used for reinforcement in the thermoplastic due to their low density, good thermal insulation and mechanical properties, reduced tool wear, unlimited availability, low price, and problem free disposal. Natural fibres and fillers are also safer to handle than synthetic fibres, example glass fibres [5]. Recently, research has focused on the use of naturally available materials such as saw dust $[6,7]$ and coconut shell powder [8,9] as filler materials for polymer matrices. The properties of their composites were found to depend on their weight percentage in the polymer matrix and filler surface treatment. Kokta et al [10] studied the mechanical behaviour of wood flour-added polypropylene composite and found that the addition of filler material in the polypropylene matrix improved the mechanical properties of the matrix.

Green composites are expected to be widely used in place of polymer composites made from fossil oil and to contribute to the maintenance of a sustainable productive society. Several green composites which consist of natural fibres as reinforcements with biodegradable resin as a matrix material are proposed such as coconut shell, flax, jute, and bamboo [4]. These composites are often desired for their advantages such as light weight, low cost, high specific modulus, and strength, in addition to their abundant availability, simplicity of surface treatment for natural fibres, and biodegradability [11].

The mechanical properties of fibre reinforced composites 
International Journal of Engineering Research and Technology. ISSN 0974-3154, Volume 13, Number 10 (2020), pp. 2742-2751

(C) International Research Publication House. https://dx.doi.org/10.37624/IJERT/13.10.2020.2742-2751

(FRCs) are dependent on the type, length and shape of fibres used. For example, randomly oriented, evenly distributed short fibres of lengths between 1-30 $\mu \mathrm{m}$ form composites that are not fully isotropic. This type of fibre reinforcement material is used mostly on low performance parts that are produced in great numbers. When FRCs use fibres that run all the length of the composite in only one direction, the mechanical properties will vary with the orientation of the applied load with reference to the orientation of the reinforcing fibre. For instance, the composite will have higher mechanical properties in the longitudinal direction of the reinforcing fibres [12].

A substantial amount of research has been carried out to determine the mechanical properties of natural fibre-based polymer composites. Biswas et al. [13] studied the effect of length on the mechanical behaviour of coir fibre reinforced epoxy composites and observed that the hardness of their composites within the range of 12.6, 15 and $16.9 \mathrm{Hv}$ decreased with the increasing length of fibre up to $20 \mathrm{~mm}$. Mohanty et al. [14] studied the effects of jute fibre on the mechanical properties of pure biodegradable polymer (Biopol). The results showed that the impact strength, tensile strength, and bending strength of the composite increased when compared with those of pure Biopol. Fibre reinforced polymers have developed as the main group of structural materials that are used as substitutes for metals in many weight critical components in the aerospace and automobile industries $[15,16,17]$.

Particle fillers are used extensively to enhance the properties of matrix materials including modifying their thermal and electrical conductivities, increasing their performance at elevated temperatures, lowering their friction, increasing their wear and abrasion resistance, improving their machinability, increasing their surface hardness and reducing their shrinkage [18]. The addition of industrial waste (Fly ash) filler to kenaf fibre nano-composites was observed to provide considerable improvement of the tensile strength of kenaf fibre nanocomposites [20]. In sago starch-filled linear low-density polyethylene (LLDPE) composites, in which sago starch acts as a filler, the mechanical properties of tensile strength and elongation at breakpoint were observed to decrease with increasing sago starch content while the modulus was found to increase [21].

The research work presented here focused on the development of a CSP/epoxy resin composite due to the high strength and stiffness of CSP, with CSP acting as the reinforcement and epoxy resin as the matrix material. The quasi-static behaviour of composites produced in this work were investigated for different filler sizes, and volume fractions.

\section{EXPERIMENTAL PROCEDURE}

\subsection{Materials}

The materials shown in Table 1 were used to prepare CSP/epoxy resin composites.
Table 1: Details of the resin system used in the present work

\begin{tabular}{|c|c|c|}
\hline \multicolumn{3}{|c|}{ Details of matrix, reinforcement, and release system } \\
\hline \multicolumn{3}{|c|}{ Matrix Details $\mu$} \\
\hline Manufacturer & \multicolumn{2}{|l|}{ Gurit } \\
\hline Resin type & \multicolumn{2}{|l|}{ Epoxy } \\
\hline $\begin{array}{l}\text { Resin } \\
\text { Identification }\end{array}$ & \multicolumn{2}{|l|}{ Prime 27} \\
\hline \multicolumn{3}{|c|}{ Matrix Hardener } \\
\hline Product Name & \multicolumn{2}{|c|}{ Prime 27 slow hardener } \\
\hline \multicolumn{3}{|l|}{ Filler Details } \\
\hline Filler material & $150 \mu \mathrm{m}$ CSP & $212 \mu \mathrm{m}$ CSP \\
\hline \multicolumn{3}{|c|}{ Release System } \\
\hline Wax & Ram Wax & Ram Wax \\
\hline
\end{tabular}

\subsection{Fabrication of Composites}

The coconut shell was dried in open air and ground into powder using a pulverizing machine. The powder was then sieved in accordance with BS 1377:1990 standard. The composite was fabricated using the method of hand lay-up. Firstly, the moulds for casting the test specimens were fabricated from glass with planer dimensions of $350 \times 550 \times 35 \mathrm{~mm}$ and a thickness of 7.5 $\mathrm{mm}$. The mould was then coated on the inside with a transparent film of "ram-wax" to facilitate removal of the cast material from the mould after curing. Coconut shell powder was then added into acetone in a glass jar and the mixture stirred at low frequency of $10 \mathrm{~Hz}$ using a scientific ultra-sonic bath at a room temperature of $23^{\circ} \mathrm{C}$ for an hour in order to ensure an even distribution of the CSP in the acetone. The suspension was then added to epoxy resin in a jar, stirred and heated to a temperature of $140^{\circ} \mathrm{C}$ in order to evaporate the acetone thus leaving behind coconut shell powder dispersed in epoxy resin.

The mixture was then placed in a scientific ultra-sonic bath and stirred for 5 minutes in order to ensure that the mixture temperature of $21^{\circ} \mathrm{C}$ was obtained throughout. Thereafter, hardener was added into the mixture in the ratio of 3.57:1 (100:28) resin: hardener as recommended and stirred thoroughly for about 10 minutes to obtain a uniform mixture. The thoroughly stirred mixture was then placed in a vacuum chamber for degassing under a $-90 \mathrm{kPa}$ vacuum for 20 minutes to remove any entrapped air bubbles. The mixture was then poured into the glass mould, sealed, and allowed to cure for 8 hours. The cured composite was later post-cured in an oven for 8 hours at $65^{\circ} \mathrm{C}$. This whole process was repeated for the different weight percentages of $(5,10,15,20,25$ and 30) of the coconut shell particles. Thereafter, the specimens were cut to standard dimensions for each test to be carried out, using a CNC machine. The specimens were then used to determine the following mechanical properties: tensile strength and stiffness, 
International Journal of Engineering Research and Technology. ISSN 0974-3154, Volume 13, Number 10 (2020), pp. 2742-2751

(C) International Research Publication House. https://dx.doi.org/10.37624/IJERT/13.10.2020.2742-2751

impact toughness, hardness in accordance with ASTM standards D638-02, ISO 179-1: 2010/ 6110-04, D2583-07, D5023-01 and ASTM: D5418-01, respectively [22, 23, 24, 25]. Schematic drawings of the test specimens used with their dimensions are shown in Figure 1. Figure 2 (a \& b) show the pouring of thoroughly mixed CSP and epoxy resin composite into a mould and the cured composite inside an enclosed glass mould, respectively.

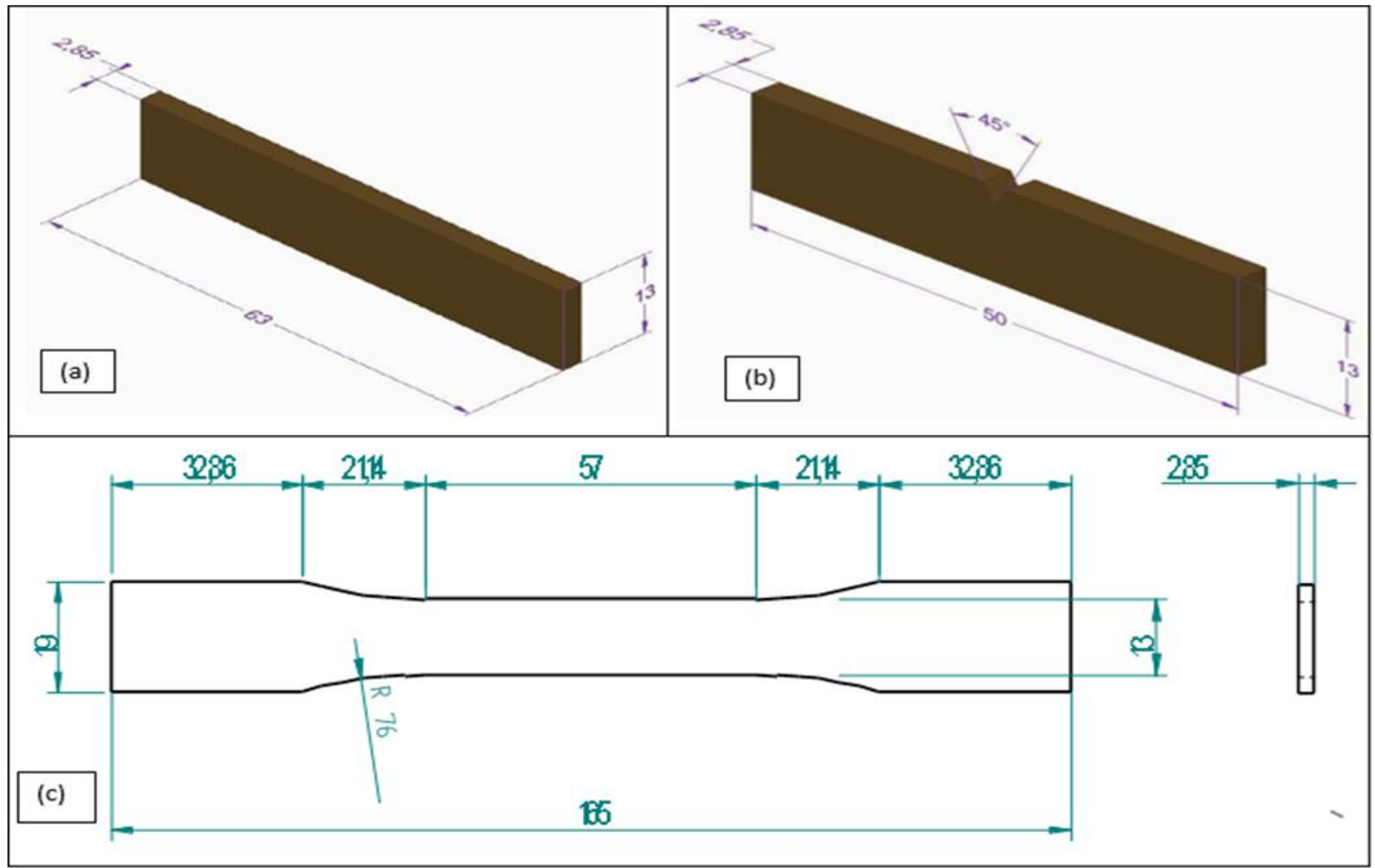

Figure 1: Schematic drawing (a) Hardness specimen according to ASTM D2583-07, (b) Charpy specimen according to ISO 179-1 and (c) Tensile specimen according to ASTM D638

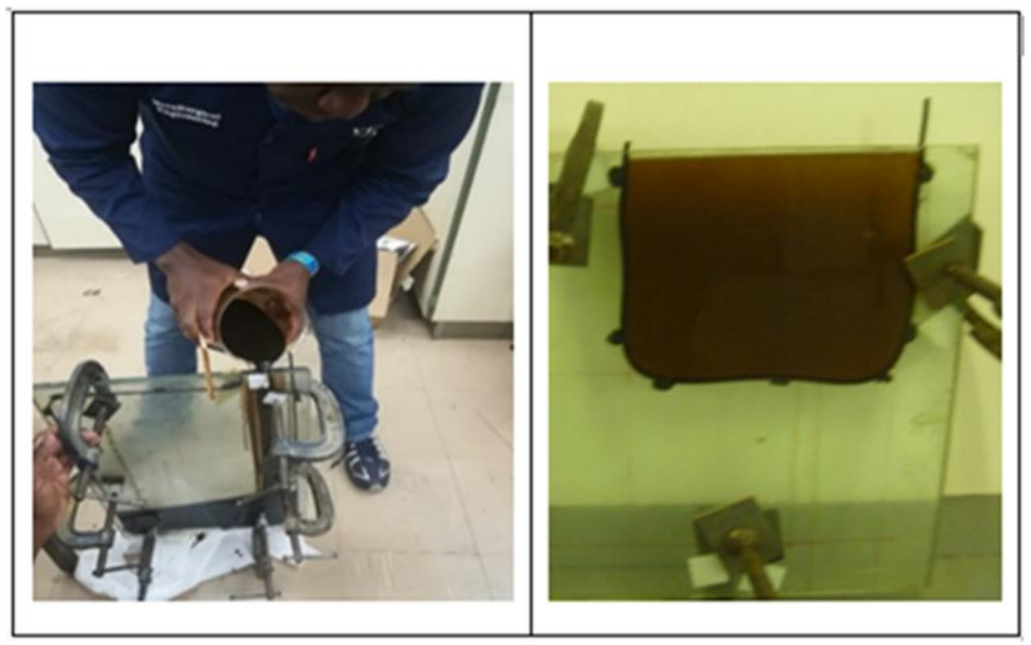

(a)

(b)

Figure 2: Pouring of the mixed reinforced coconut shell powder composite into the mould and the cast CSP epoxy resin/coconut particle composites 


\subsection{Mechanical testing}

\subsubsection{Tensile Testing}

Dog-bone test specimens with a rectangular cross-section, prepared according to ASTM D638 as shown in Figure 3, were used for tensile testing.

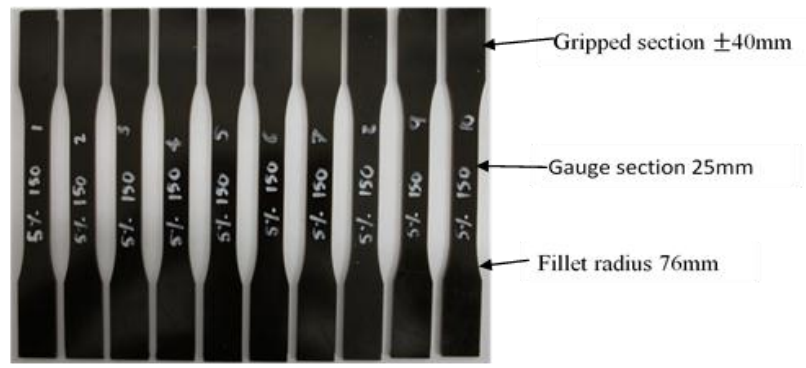

Figure 3: Dog bone tensile test specimens (ASTM D638)

Testing was performed with the Lloyd LR30k tensile testing machine shown in Figure 4 with a $30 \mathrm{kN}$ load cell. The Epsilon extensometer with a gauge length of $25.00 \mathrm{~mm}$ and a maximum travel of $2.50 \mathrm{~mm}$ shown in the same Figure, was used to determine the extension of the specimen during the test. Ten identical specimens were tested, and average results calculated. All tensile testing was conducted at a room temperature of $23^{\circ} \mathrm{C}$ and at a constant crosshead speed of $5 \mathrm{~mm} / \mathrm{min}$. Specimens of the dog-bone type shown in Figure 3 with a rectangular crosssection were used for testing.

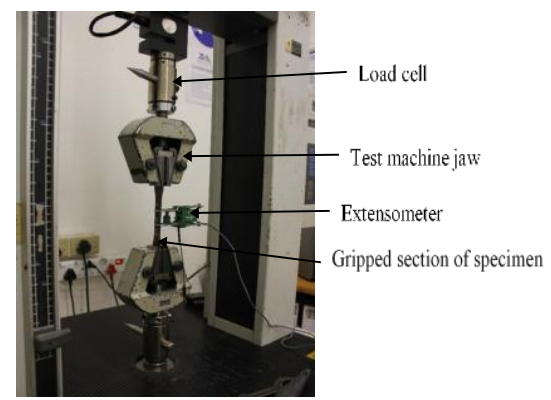

Figure 4: Lloyd LR30k tensile testing machine

Only 8 of the 10 specimens of $10 \% 150 \mu \mathrm{m}$ that were tested failed within the gauge length as seem in Figure 5.

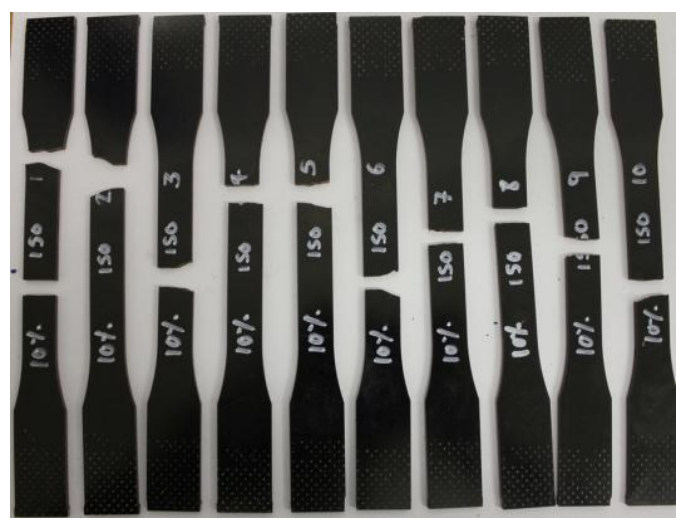

Figure 5: 10 weight percentage of $150 \mu \mathrm{m}$ size CSP in epoxy resin composite specimens after tensile testing to failure

\subsubsection{Charpy Impact Testing}

The impact strength of specimens were determined according to the ISO 179-1: 2010/ ASTM 6110-04 test standards. Testing was performed utilising a Hounsfield Balanced Impact Machine. Test specimens were prepared according to ISO1791: 2010/6110-04 ASTM, with a $45^{0} \mathrm{~V}$-notch cut into the side each specimen as shown in Figure 1 (b). 10 identical specimens were used to determine the impact strength of composites for each type of composite.

\subsubsection{Hardness Testing}

The Barcol hardness of test specimens were determined according to ASTM: D2583-07. A Barber Colman - GYZJ 934-1 hardness impresser was first calibrated using the Colman calibration disks and then utilized for the test. For each composition, ten identical specimens were tested, and average results and standard deviation calculated.

\section{RESULTS AND DISCUSSION}

The results of tensile strength, tensile elastic modulus, percentage elongation, Charpy impact toughness and hardness of CSP/epoxy resin composites with different weight percentages of the CSP filler are presented in Figures 6-11, together with their accompanying discussions.

\subsection{Tensile Strength and Elastic Modulus}

Figure 6 shows the effect of CSP filler content (percentage weight) and particle size on the tensile strength of CSP/epoxy resin composites.

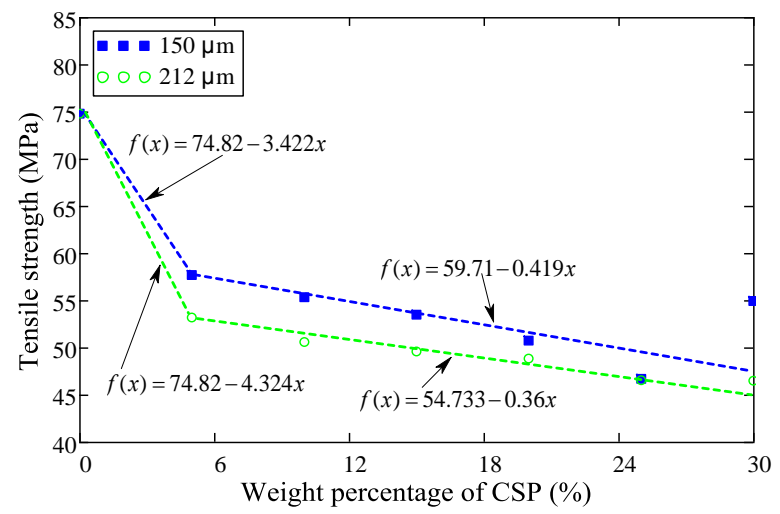

Figure 6: Tensile strength of CSP/epoxy resin composites versus weight percentage of the reinforcing CSP filler

The tensile strength of pure epoxy resin was determined as 75 $\mathrm{MPa}$. It is clear from Figure 6 that for both the $150 \mu \mathrm{m}$ and 212 $\mu \mathrm{m}$ filler particle epoxy resin composites, the effect of reinforcement was a continuous decrease of tensile strength with increasing addition of filler. For both filler particle sizes, two linear curves are evident in the figure, with initial steeper gradients up to a filler volume fraction of about $5 \mathrm{wt} \%$. The tensile strength of the composite is seen to be lower for the 
larger size filler particles at all weight fractions of the reinforcing filler. Similar results were observed for groundnut shell particles reinforced epoxy composites [26] and for periwinkle shell particles reinforced polyester composites [27]. This decreasing trend is thought to be as a result of the weak interfacial bonding between the CSP filler and epoxy resin matrix due to increasing agglomeration with increasing filler weight fraction. Weak interfacial bonding leads to inefficient transfer of the stresses between the matrix and CSP filler thus giving rise to weaker composites [28]. Poor dispersion of the Nano fillers has been observed elsewhere to be the main factor that results in poor wetting and/or impregnation of reinforcing fibre, thus compromising mechanical strength, and is likely to be a contributing factor here as well [29, 30, 31].

The results of filler particle size and filler weight fraction on the elastic modulus of CSP/epoxy resin composites is shown in Figure 7.

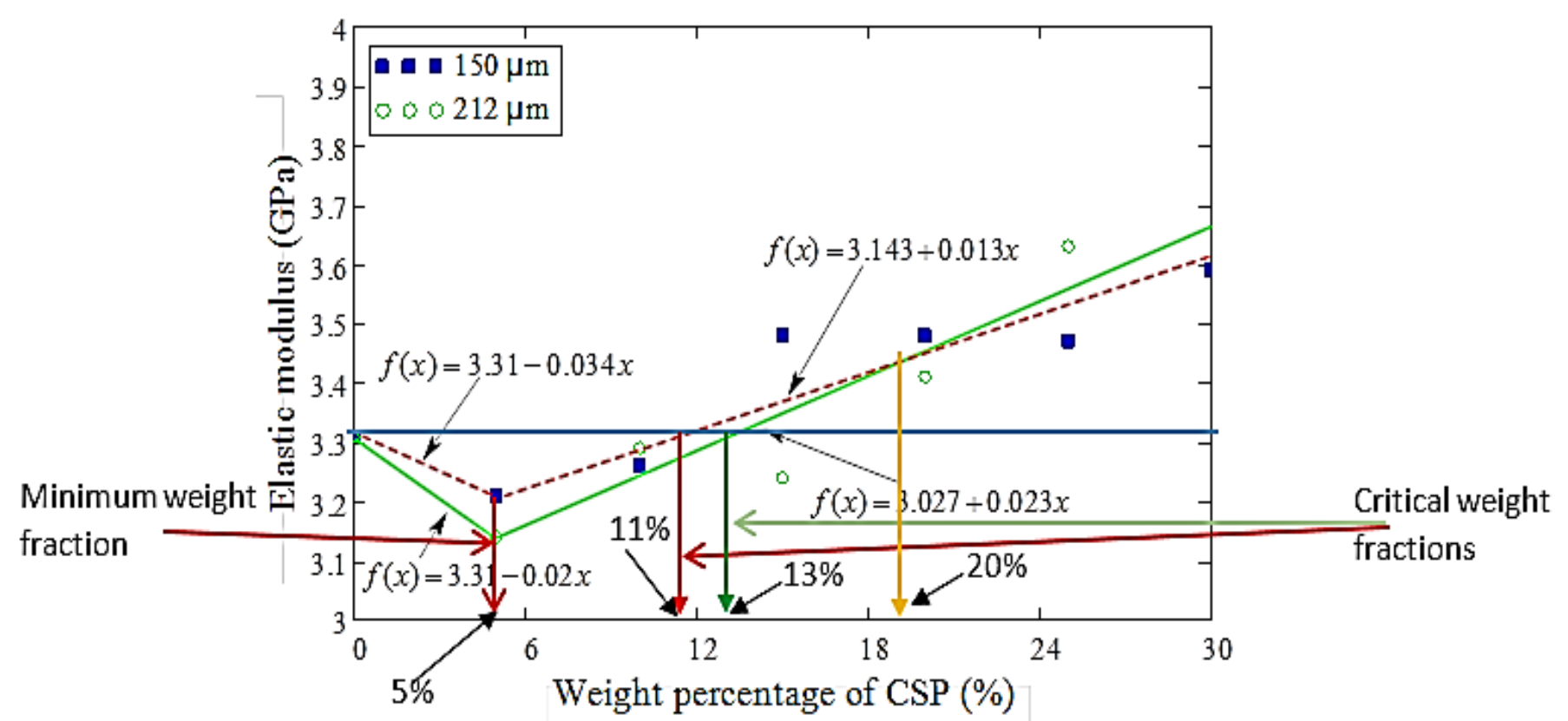

Figure 7: Elastic modulus of CSP/epoxy resin composites versus weight percentage of the reinforcing CSP filler

The Young modulus for the pure epoxy resin was determined as 3.31 GPa. Both curves in Figure 7 exhibit an initial decrease of Young modulus up till minimum values at a weight fraction of $5 \%$. There was improvement in the Young modulus of the $150 \mu \mathrm{m} \mathrm{CSP/epoxy} \mathrm{resin} \mathrm{composites} \mathrm{over} \mathrm{that} \mathrm{of} \mathrm{the} \mathrm{pure}$ epoxy resin above the critical weight fraction of $11 \mathrm{wt} \%$. The same applied to samples of $212 \mu \mathrm{m}$ CSP/epoxy resin composites with a critical weight fraction of $13 \mathrm{wt} \%$. This shows that the introduction of coconut shell powder into epoxy resin matrix, leads to an initial decrease and an eventual increase in the magnitude of the elastic modulus of the CSP/epoxy resin composites. Both of these trends are consistent with standard theory of reinforcement. While the 150 $\mu \mathrm{m}$ CSP/epoxy resin filler composites had higher values of stiffness at lower weight fractions, the converse is true at higher weight fractions above $20 \mathrm{wt} \%$. This phenomenon may be as a result of poor interaction of the CSP with the epoxy resin with increasing filler contents of CSP.

In Figure 8 the percentage elongation to failure of CSP/epoxy resin reinforced composites are plotted for filler contents of $0,5,10,15,20,25$, and $30 \%$ weight of $150 \mu \mathrm{m}$ and $212 \mu \mathrm{m}$ particle sizes of CSP.

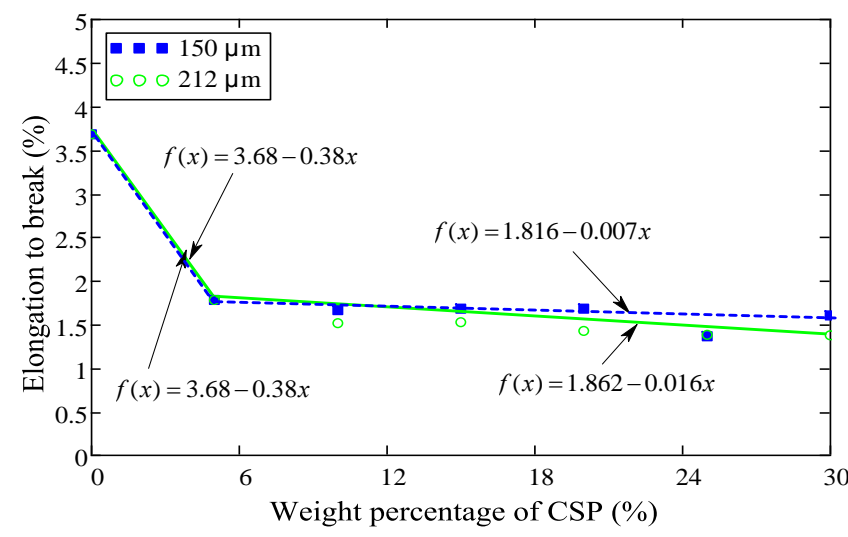

Figure 8: Percentage elongation of CSP/epoxy resin composites versus percentage weight CSP reinforcing filler

Figure 8 shows the percentage elongation to failure of the CSP/epoxy resin composites to decrease continuously with increasing content of CSP reinforcing filler for both filler particle sizes. The two curves both show a large initial drop in value between 0 and $5 \mathrm{wt} \%$ for the CSP/epoxy resin composites of both $150 \mu \mathrm{m}$ and $212 \mu \mathrm{m}$ particles. This is followed by a gradual and continuous decrease of the percentage elongation 
to failure with increasing weight fraction of the reinforcing CSP filler but at a lower rate. The decreasing trend was due to the higher rigidity of coconut shell-based nanoparticles than that of epoxy resin. The increase of filler reduces their mobility as result of crowding and therefore gives rise to an increase in brittleness of the filler reinforced composite. Another reason for the trend is that an increase of the content of filler leads to agglomeration of the filler particles instead of dispersion, which leads to weaker interfacial bonds and smaller surface areas for bonding. Coconut shell powder filler offers increased resistance to crack propagation in the composite [32]. As a result, there is a decrease of the percentage elongation of composites with CSP filler as compared to the neat epoxy resin. It is also noted that the percentage elongation of the lower particle size composites is lower at lower filler weight percentages and higher at higher filler weight percentages than the bigger particle size composites. This is likely to be a result of higher dispersion at lower volume fractions and less agglomeration at higher volume fractions, of the smaller than bigger particle size composites.

\subsection{Charpy Impact Toughness}

Figure 9 shows the Charpy impact toughness of CSP/epoxy resin reinforced composite for filler contents of $0,5,10,15,20,25$, and $30 \%$ weight for $150 \mu \mathrm{m}$ and $212 \mu \mathrm{m}$ particle sizes of the CSP filler.

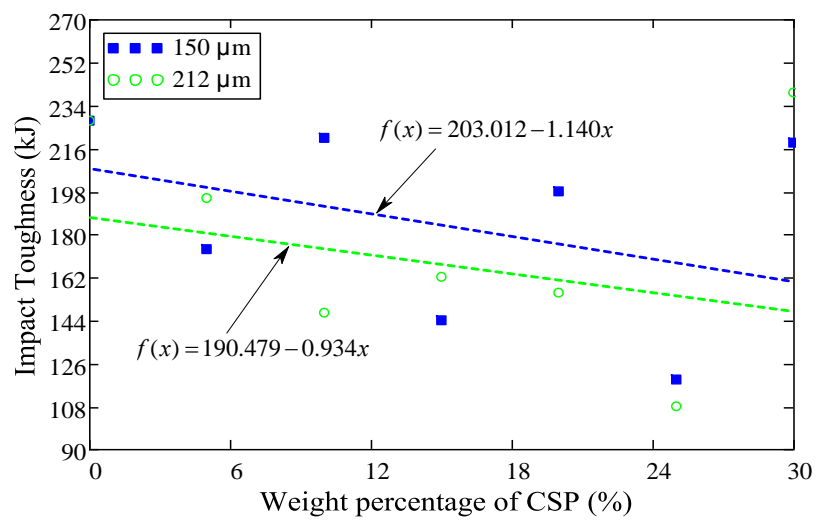

Figure 9: Charpy impact toughness versus weight percentage of CSP reinforcing filler versus weight percentage of filler

Though the values of Charpy impact toughness shown in Figure 9 exhibit a large scatter, there is a general declining trend of impact toughness with increasing percentage weight of CSP filler. This is as a result of lack of good adhesion between filler and matrix and less effective reinforcement both arising from increasing agglomeration with increasing filler weight percentage. The $150 \mu \mathrm{m}$ CSP particle composites exhibit higher values of impact toughness compared to the $212 \mu \mathrm{m}$ CSP particle composites. This trend is likely to be due to the fact that the smaller particles provide more crack arrest points for the same volume fraction and therefore enhance the toughness of the matrix more effectively.
Table 2 shows the values of Barcol hardness that were determined experimentally for epoxy resin, as well as, for both the CSP $150 \mu \mathrm{m}$ and $212 \mu \mathrm{m}$ particle size epoxy resin composites, for different weight fractions of CSP.

Table 2: Barcol hardness for $150 \mu \mathrm{m}$ and $212 \mu \mathrm{m}$ CSP particle size epoxy resin composites

\begin{tabular}{|l|c|}
\hline Sample type & $\begin{array}{c}\text { Hardness } \\
\text { (BHa) }\end{array}$ \\
\hline Neat epoxy resin & $31.0 \pm 2.11$ \\
\hline $5 \% 150 \mu \mathrm{m}$ CSP/epoxy resin composites & $36.0 \pm 1.34$ \\
\hline $10 \% 150 \mu \mathrm{m}$ CSP/epoxy resin composites & $37.0 \pm 1.43$ \\
\hline $15 \% 150 \mu \mathrm{m}$ CSP/epoxy resin composites & $41.0 \pm 2.01$ \\
\hline $20 \% 150 \mu \mathrm{m}$ CSP/epoxy resin composites & $44.0 \pm 0.94$ \\
\hline $25 \% 150 \mu \mathrm{m}$ CSP/epoxy resin composites & $46.0 \pm 0.99$ \\
\hline $30 \% 150 \mu \mathrm{m}$ CSP/epoxy resin composites & $46.0 \pm 1.72$ \\
\hline $5 \% 212 \mu \mathrm{m}$ CSP/epoxy resin composites & $36.0 \pm 1.51$ \\
\hline $10 \% 212 \mu \mathrm{m}$ CSP/epoxy resin composites & $37.0 \pm 1.17$ \\
\hline $15 \% 212 \mu \mathrm{m}$ CSP/epoxy resin composites & $41.0 \pm 2.08$ \\
\hline $20 \% 212 \mu \mathrm{m}$ CSP/epoxy resin composites & $44.0 \pm 1.25$ \\
\hline $25 \% 212 \mu \mathrm{m}$ CSP/epoxy resin composites & $46.0 \pm 1.06$ \\
\hline $30 \% 212 \mu \mathrm{m}$ CSP/epoxy resin composites & $46.0 \pm 2.27$ \\
\hline
\end{tabular}

Figure 10 shows the values of mean Barcol hardness of CSP/epoxy resin composites for CSP filler contents of $0 \%, 5 \%$, $10 \%, 15 \%, 20 \%, 25 \%$ and $30 \%$ weight of 150 and 212 particle size of CSP, plotted against respective values of standard deviation

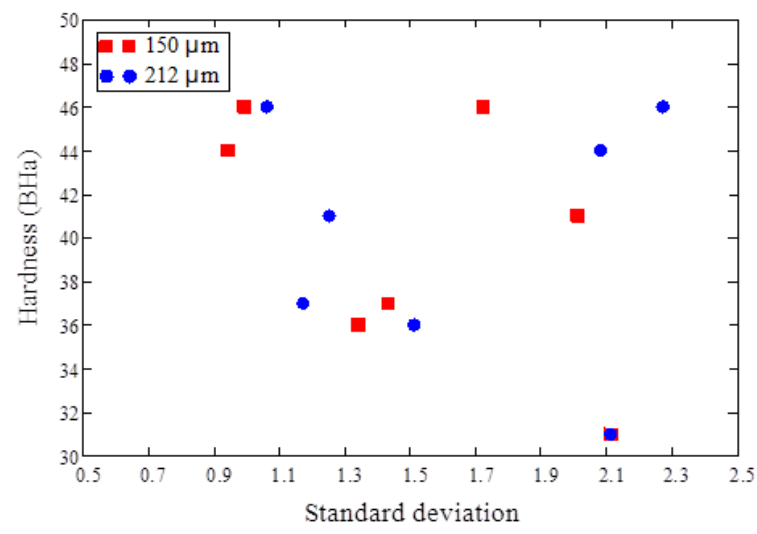

Figure 10: Values of mean Barcol hardness versus standard deviations for CSP/ epoxy resin composites for $150 \mu \mathrm{m}$ and $212 \mu \mathrm{m}$ CSP sizes. 
A general trend emerges from the curves in Figure 10 of decreasing standard deviation with increasing mean Barcol hardness. This is expected as increasing hardness of the composite is a result of increased filler content, as is evident in the next figure, whose hardness is higher than that of the matrix.

Figure 11 shows the values of Barcol hardness results of CSP/epoxy resin composites for CSP filler contents of $0 \%, 5 \%$, $10 \%, 15 \%, 20 \%, 25 \%$, and $30 \%$ weight of $150 \mu \mathrm{m}$ and $212 \mu \mathrm{m}$ particle sizes of CSP, plotted against the weight fractions of filler.

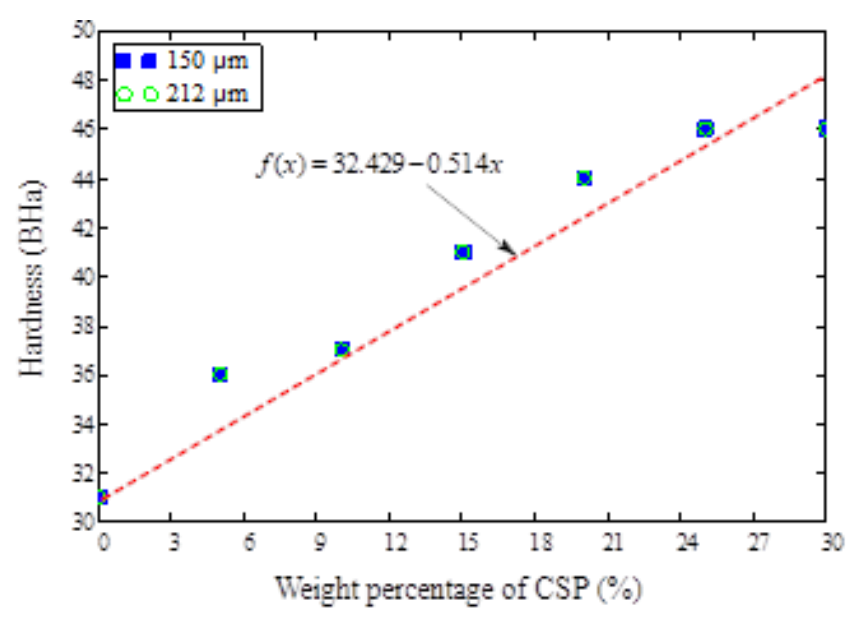

Figure 11: Effect of the percentage weight of CSP reinforcing filler on the hardness of CSP/ epoxy resin composites for 150 $\mu \mathrm{m}$ and $212 \mu \mathrm{m}$ CSP sizes

It is evident from Figure 11 that, the hardness of CSP/epoxy resin composites increases continuously with increasing reinforcing filler's content for both the $150 \mu \mathrm{m}$ and $212 \mu \mathrm{m}$ CSP filler particles. The effect of reinforcing particle size is seen in the figure to be minimal as the two curves are more or less coincident at all weight fractions plotted.

\subsection{Comparing Theoretical and Experimental Mechanical Properties of CSP/Epoxy Resin Composites}

The particulate filler phase has been studied with reference to of weight fraction and particle sizes [27, 33]. It has been shown in research that for a given particulate volume fraction, the composite strength increases with decreasing particle size, and increasing volume fraction of the reinforcing filler [21, 27]. As a result, a variety of models are available to describe the modulus, tensile strength, and elongation at rapture as a function of filler volume fraction and particle sizes [33, 34]. The modulus and yield strength of particle-filled composites can be predicted from a number of models described by the Einstein equations, Guth and Smallwood model, Voigt rule Reuss model, and Kerner's equation, presented here as Equations 1 and 2, 3, 4 and 5, and from Nicolais-Narkis' equation presented here as Equations 6 and 8 [27, 34]. Expressions to predict the tensile strength of a particulate-filled composite from the UTS of the matrix $\left(\sigma_{\mathrm{m}}\right)$ and the volume fraction $\left(\mathrm{V}_{\mathrm{p}}\right)$ of the reinforcing filler are presented here as
Equations 1- 4 and 6-10. The equations show the strength of particulate-filled composites such as the coconut shell powder reinforced composite in the present study decreases with the increase in the percentage weight of reinforcing filler. Nielsen's equation, presented here as Equation 11, developed a basic model to describe the elongation of particulate composites at rapture, assumed perfect adhesion and therefore, fracture of the , polymer at the same elongation in the filled system as in the neat polymer [35].

$$
\begin{aligned}
& E_{C}=E_{m}\left(1+\mathrm{V}_{\mathrm{p}}\right) \\
& E_{c}=E_{m}\left(1+2.5 V_{p}\right) \\
& E_{c}=E_{m}\left(1+2.5 V_{p}+14.1 V_{p}^{2}\right) \\
& E_{c}=E_{-} m v_{m}+E_{p} V_{p} \\
& E_{c}=\frac{E_{m} E_{P}}{E_{m} V_{p}+E_{p} V_{m}} \\
& \sigma_{y c}=\sigma_{y m}\left(1-1.21 V_{p}^{2 / 3}\right) \\
& \sigma_{y}=\sigma_{m}\left(1-V_{p}\right) \\
& \sigma_{y}=\sigma_{y m}\left(1-2.5 V_{p}\right) \\
& \sigma_{c}=\sigma_{m} V_{m}+\sigma_{p} V_{p} \\
& \sigma_{c}=\frac{\sigma_{m} \sigma_{P}}{\sigma_{m} V_{p}+\sigma_{p} V_{m}} \\
& \epsilon_{c}=\epsilon_{m}\left(1-V_{p}^{1 / 2}\right)
\end{aligned}
$$

Figure 12 shows both the experimental and predicted values of the tensile strength for CSP epoxy resin composites.

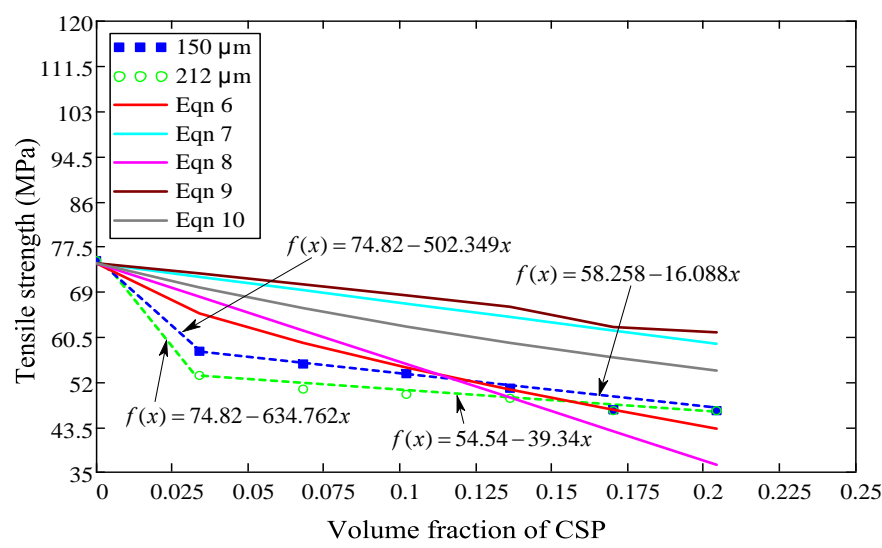

Figure 12: Comparison of experimental data with predicted data for tensile strength 
The curves in Figure 12 show both the experimental and predicted values of the tensile strength to decrease with an increase in the volume fraction of the coconut shell powder. Both the experimental and results predicted from Equations 7, 8,9 and 10 show linear decrease with the increasing volume fraction of the reinforcing filler, the former in two stages and the latter in a single stage. The results predicted from the theory of Nicolais-Narkis (Equation 6 and 8) are non-linear and linear, respectively, and are both closer to the experimental results, compared with those from Equations 7, 9 and 10, all which exhibit higher values than the experimental results. This shows that Equation 6 and 8 are best suited to predict the strength of this composite over the volume fraction range considered.

Experimental and theoretical curves of the variation in the magnitude of the modulus of elasticity of CSP reinforced epoxy composites for particle dimensions of $150 \mu \mathrm{m}$ and $212 \mu \mathrm{m}$ versus volume fraction are presented in Figure 13.

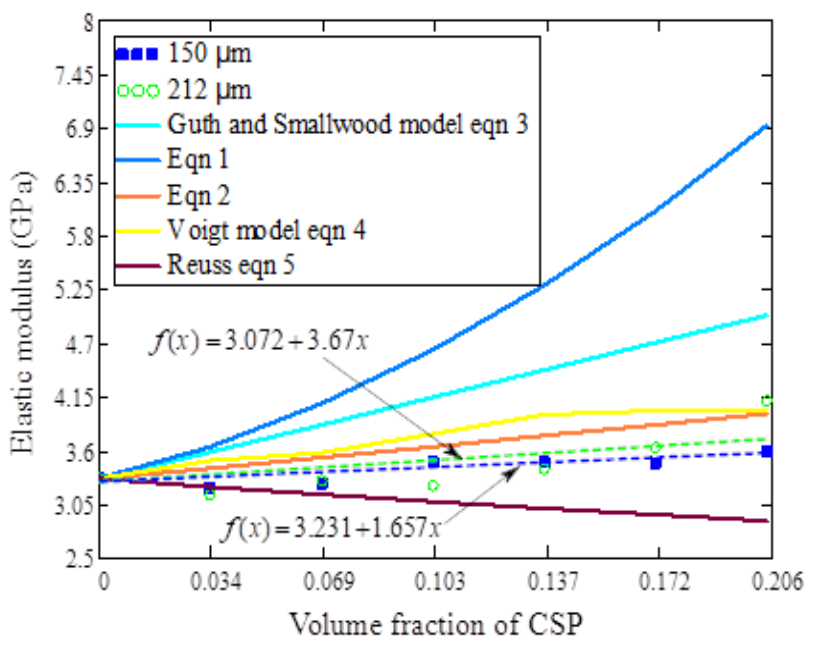

Figure 13: Comparison of experimental data with predicted data for elastic modulus

The experimental results presented in this Figure are compared with values calculated from the Einstein Equation's 1 and 2, Guth and Smallwood Equation 3 as well as the Voigt and Reuss Equations 4 and 5. The curves for Einstein's Equations 1 and 2, Guth and Smallwood Equation 3, and the Voigt rule exhibit values that are higher than the experimental results. The curve for Reuss model Equation 5 shows values that are less than the experimental values with a difference that increases with increasing volume fraction of the reinforcing filler in the range of volume fractions shown in the figure. This may be as a result of non-uniform spherical filler particle adhering well to the polymer matrix.

The curve for Guth and Smallwood Equation 3 exhibits values that are close to the experimental results with a difference that increases with increasing volume fraction of the reinforcing filler. Because it predicts reinforcement, Guth and Smallwood Equation 3 is best suited to predict the elastic modulus of the CSP/epoxy resin composite over the volume fraction of reinforcing filler investigated in this work.
Figure 14 shows a comparison of the experimental and theoretical values for percentage elongation for CSP epoxy resin composites

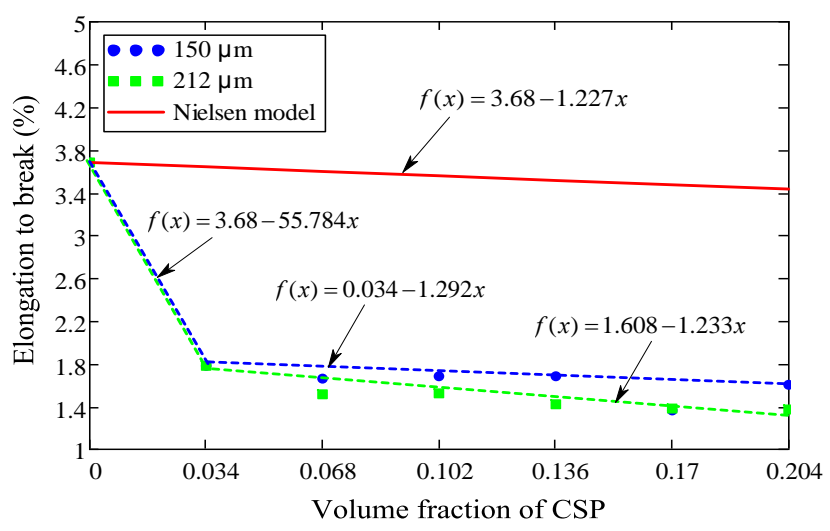

Figure 14: Comparison of experimental data with predicted data for elongation to rapture

The predicted values of percentage elongation from Nielsen's model Equation 11, decrease linearly with increasing volume fraction, the same as the experimental values. However, the latter shows two stage curves, with an initial steep gradient till a volume fraction of $0.34 \%$. The experimental results are, however, much less than the predicted results. This may be as a result of poor adhesion that minimises the reinforcing effect of the fillers in comparison with the expectations based on theoretical models.

\subsection{CONCLUSIONS}

The following conclusions can be drawn from this work:

1) The mechanical properties of tensile strength, stiffness, percentage elongation, as well as toughness and hardness for CSP/epoxy resin composites are all affected by the size and content of CSP fillers.

2) The curves for stiffness exhibited the standard variations with weight fraction that are common to reinforced composites, complete with minimum and critical weight fractions. The larger particle sizes composites give rise to more effective reinforcement up to a weight fraction of $20 \%$ of the CSP filler and are less effective above this value.

3) Though a continuous reduction in the tensile strength and impact toughness of CSP/epoxy resin composites with increasing weight percentage of CSP filler particles of both sizes was observed, the effect was less for composites of the smaller particle size.

4) Coconut shell particle filled epoxy resin composites exhibited values of hardness that increased continuously with increasing percentage weight of CSP fillers and showed no discernible effect of filler particle size. 
5) While the stiffness and hardness of CSP/epoxy resin composites showed an improvement on the values for raw epoxy resin, the former beyond a critical value of reinforcing filler volume fraction, the tensile strength, percentage elongation and toughness all decreased with the addition of CSP filler. The use of CSP as a reinforcing filler must therefore be for purposes of enhancing the first two mechanical properties, with the attendant reduction in the other three mechanical properties being taken on board

6) Different models were used to predict the mechanical properties of the CSP composites.

- The values of the tensile strength predicted by the Nicolais-Narkis theory (Equations 6 and 8) and by Equations 7, 9 and 10 showed decreasing trends of tensile strength with increasing weight fraction of the reinforcing filler with the curves for equations 6 and 8 fitted best to the experimental results.

- The values of the elastic moduli predicted by the Einstein Equations 1 and 2, Voigt Equation 4, and Guth and Smallwood Equation 3 showed values that were higher than the experimental results. The Reuss model Equation 5 exhibited values that were lower than the experimental results. Of all these models, Guth and Smallwood Equation 3 fitted best to the experimental results.

- The results of elongation to break that were predicted from Nielsen's Equation 11 were significantly different from the experimental results, possibly due to power interfacial adhesion between the filler particles and the matrix.

\subsection{RECOMMENDATIONS}

A study of a wider range of CSP particle sizes is recommended in order to determine trends and an optimum particle size.

\section{CONFLICT OF INTEREST}

The researchers have no conflict of interest to disclose with regard to the current research work.

\section{ACKNOWLEDGEMENT}

This research work was supported by the Vaal University of Technology (VUT), South Africa and Council for Scientific and Industrial Research (CSIR), South Africa.

\section{REFERENCES}

[1] Mohanty A. K., Misra M., and Drzal, L. T., J., 2002, Polymer Environment, Germany, pp. 10-19.

[2] RAO, M.D., 2003, "Recent applications of viscoelastic damping for noise control in automobiles and commercial airplanes". Journal of Sound and Vibration, 262(3), pp. 457-74.
[3] Neitzel, I., Mochalin, V., Koki, I., Palmese, G. R., and Gogotsi, Y., 2011, "Mechanical properties of epoxy composites with high contents of nanodiamond". Composite Science Technology, 71(5), pp. 710-6.

[4] Mohammed, L., Ansari, M.N.M., Pua, G., Jawaid, M., and Saiful Islam, M., 2015, "A review of natural fibre reinforced polymer. Composite and Its Application". International Journal of Polymer Science. Pp. 1-15.

[5] Kinoshita, H., Kaizu, K., Fukuda, M., Tokunaga, H., Keisuke Koga, K., and Ikeda, K., 2009, "Development of green composite consists of woodchips, bamboo fibres and biodegradable adhesive". Composite Part B: Engineering, Vol. 40, pp. 607-612.

[6] Khalil, H. P. S. A., Shahnaz, S. S., Ratnam, M. M., Ahmad, F., and Fuaad, N. N., 2006, "Recycle polypropylene (RPP) - wood saw dust (WSD) composites-Part 1: The effect of different filler size and filler loading on mechanical and water absorption properties". J. Reinf. Plast. Compos. 25(12), pp. 129113037.

[7] Dos Santos, L. P., Flores-Sahagun, T. S., and Satyanarayana, K. G., 2015, "Effect of processing parameters on the properties of polypropylene-sawdust composites". J. Compos. Mater. 49(30), pp. 3727-3.

[8] Sarki, J., Hassan, S. B., Aigbodion, V. S., and Oghenevweta, J. E., 2011, Potential of using coconut shell particle fillers in eco-composite materials. J. Alloys Compd. 509(5), pp. 2381-2385.

[9] Chun, K. S., Husseinsyah, S., and Azizi, F. N., 2013, "Characterization and properties of recycled polypropylene/ coconut shell powder composites": Effect of sodium dodecyl sulfate modification. Polym. Plast. Technol. Eng. 52(3), pp. 287-2.

[10] Kokta, B. V., Raj, R. G., and Daneault, C., 1989, "Use of wood flour as filler in polypropylene : Studies on mechanical properties". Polym. Plast. Technol. Eng. 28(3), pp. 247-259.

[11] Heckadka, S.S, Nayak, S.Y, Vikas, S.R., and Kini, M.V., 2016. "Investigation of tensile strength for areca frond/corn starch composites". Indian Journal of Science, 9(35).

[12] Frangopol, D.M., and Recek, S., 2003, "Reliability of fiber-reinforced composite laminate plates". Probabilistic Engineering Mechanics. Vol.18, pp. 119137.

[13] Biswas, S., Kindo, S., and Patnaik, A., 2011, "Effect of length on coir fibre reinforced epoxy composites". Fiber and Polymers, Vol.12, pp. 73-78.

[14] Mohanty, A.K., Khan, M.A., and Hinrichen, G., 2000, "Surface medication of jute and its influence on performance of biodegradable jute-fabric/Biopol composites". Composite Science and Technology. 60(7), pp. 1115-1124.

[15] Mallick, P.K., 1993, "Fiber-Reinforced Composites". [Online]. Marcel Dekker: New York. Available at https://books.google.co.za/books/about/Fiber_Reinforc ed_Composites.html?id=z0MIzzOFMqkC\&redir_esc= y. Accessed on the $13^{\text {th }}$ of August 2016. 
[16] Choi, S., and Sankar, B.V., 2008, "Gas permeability of various graphite/epoxy composite laminates for cryogenic storage systems". Part B, Vol.39, pp. 782-791. [Online]. Available at, http//www.sciencedirect.com. Accessed on the $12^{\text {th }}$ of February 2017.

[17] Pervaiz, M., Panthapulakkal, S., Birat, K.C, Sain, M., and Tjong, J., 2016, "Emerging trends in automotive light-weighting through novel composite materials". Material Science and Application, Vol.7, pp. 26-38. [Online]. Available at, http://dx.doi.org/10.4236/msa.2016.71004. Accessed on the $12^{\text {th }}$ September 2016.

[18] Verma, D., Cope, P.C., Shandilya, A., Gupta, A., and Maheshwari M.K., 2013, "Coir fibre reinforcement and application In polymer composite": A review. Journal of Material Environment Science, 4(2), pp. 263-276.

[19] Okubo, K., Fujii, T., and Yamamoto, Y., 2004, "Development of bamboo-based polymer composites and their mechanical properties". Composites Part A: Applied Science and Manufacturing, 35(3), pp. 377-383.

[20] Kumar, P. A, Mohamed, M. N, Philips, K.K., and Ashwin, J., 2016, "Development of novel natural composites with fly ash reinforcements and investigation of their tensile properties". Applied Mechanics and Materials, Vol. 852, pp. 55-60. [Online] Available https://www.researchgate.net/publication/307881349 Development_of_Novel_Natural_Composites_with_Fl y_Ash_Reinforcements_and_Investigation_of_their_Te nsile_Properties. Accessed on the $12^{\text {th }}$ October 2016.

[21] Nawang, R., Danjaji, I., Ishiaku, U., Ismail, H., and Mohd Ishak, Z., 2001, "Mechanical properties of sago starch-filled linear low-density polyethylene (LLDPE) composites", Polymer Testing, 20(2), pp. 167-172.

[22] Standard Test Method for Tensile Properties of Plastics D638M- 87b, Annual Book of ASTM Standard, Volume 08.01 Plastics (I): D 256 - D 3159, 1988.

[23] Standard Test Method for Unnotched Cantilever Beam Impact Resistance of Plastics, Designation: D 4812 - 99, Annual Book of ASTM Standard, Volume 08.02 Plastics (II): D 3222 - D 5083, 2007.

[24] Standard Test Method for Indentation Hardness of Rigid Plastics by Means of a Barcol Impressor, Designation: Annual Book of ASTM Standard, D 2583 - 07, Annual Book of ASTM Standard, Volume 08.01 Plastics (I): D256-D 3159(2007).

[25] Standard Test Method for Plastics: Dynamic Mechanical Properties: In Flexure (Three Point Bending), Designation: Annual Book of ASTM Standard, D 5023 - 01, Annual Book of ASTM Standard, Volume 08.02 Plastics (I): D256-D 3159(2001).

[26] Raju, G.U., and Kumarappa, S., 2011, "Experimental study on mechanical properties of groundnut shell particle reinforced epoxy composites". Journal of Reinforced Plastics and Composites, Vol.30, pp. 10291037.

[27] Njoku, R.E., Okon, A.E., and Ikpaki, T.C., 2011, "Effects of variation of particle size and weight fraction on the tensile strength and modulus of periwinkle shell reinforced polyester composite", Nigerian J. Technol. Vol. 30, pp. 87-93.

[28] Ma, P. C., and Kim, J. K., 2011, "Carbon Nanotubes for Polymer Reinforcement”, CRC Press, Boca Raton, FL, USA.Doi: 10.4028/www.scientific.net/AMR.879.90.

[29] Ajayan, P. M., Suhr, J., and Koratkar, N., 2006, "Utilizing interfaces in carbon nanotube reinforced polymer composites for structural damping". Journal of Materials Science 41(23), pp. 7824-7829. DOI: 10.1007/s10853-006-0693-4.

[30] Tarfaoui, M., Lafdi, K., and El Moumen, A., 2016, "Mechanical properties of carbon nanotubes-based polymer composites," Composites Part B: Engineering 103:113- $121 . \quad$ DOI: 10.1016/j.compositesb.2016.08.016.

[31] Tehrani, M., Boroujeni, A. Y., Hartman, T. B., Haugh, T. P., Case, S. W., and Al-Haik, M. S., 2013, "Mechanical characterization and impact damage assessment of a woven carbon fiber reinforced carbon nanotube-epoxy composite," Composites Science and Technology Vol. 75, pp. 42-48. DOI: 10.1016/j.compscitech.2012.12.005

[32] Islam, M.D, Das, S., Saha, J., Paul, D., Islam, M., Rahman, M., and Khan, M., 2017, "Effect of Coconut Shell Powder as Filler on the Mechanical Properties of Coir-polyester Composites". Chemical and Materials Engineering. Vol.5, pp. 75-82. 10.13189/cme.2017.050401.

[33] Fu, S.Y., Feng, X.Q., Lauke, B., and Mai, Y.W. 2008, "Effects of particle size, particle/matrix interfacing adhesion and particle loading on mechanical properties of particulate-polymer composites". Composite: Part B,39:933-961.

[34] Bourkas, G., Prassianakis, I., Kytopoulos, V., Sideridis, E., and Younis, C., 2010, "Estimation of elastic moduli of particulate composites by new models and comparison with moduli measured by tension, dynamic, and ultrasonic tests". Advances in Materials Science and Engineering, 13 doi:10.1155/2010/891824

[35] Kaully, T., Siegmann, A., and Shacham, D., 2008, "Mechanical behaviour of highly filled natural $\mathrm{CaCO} 3$ composites: effect of particle size distribution and interface interactions". Polymer composites, 29(4), pp. 396-408. 